\title{
Microstructure of the Cast Iron Materials for Sintering Machine Trolley
}

$$
\text { YANG } \mathrm{Li}^{1, \mathrm{a}} \text {, GUI Yongliang }{ }^{1, \mathrm{~b}}, \text { ZHANG Wei } \mathrm{i}^{2, \mathrm{c}}
$$

${ }^{1}$ Key Laboratory of Hebei Province Modern Metallurgy Technology, College of Metallurgy and Energy, Hebei United University, 46 Xinhua West Road,Tangshan 063009, PR China;

${ }^{2}$ Modern Technology and Education Center, Hebei United University, 46 Xinhua West Road,Tangshan 063009, PR China

asjzxj126@126.com, bgyl@heut.edu.cn, cguiyongliang@gmail.com

\section{Keywords:Carbide, Austenite, High chromium cast iron}

\begin{abstract}
The microstructure of the cast iron materials for sintering machine trolley is analyzed by the optical microscope,scanning electron microscopy (SEM),X-ray diffraction(XRD) and the energy dispersive spectroscopy (EDS). The results show that the austenite, carbide and some martensite are contained in the microstructure of the cast iron materials for sintering machine trolley.
\end{abstract}

\section{Introduction}

The sintering machine trolley works in a cold-hot-cold environment for a long time. The microstructure in the sintering machine trolley may be changed because of the thermal fatigue. Due to the thermal cycling and the combustible products which the trolley contacts with, some cracks and deformation are generated in the trolley. The upper part of the trolley is burned strongly by the hot gas. The metal where is burned is lost. The factors make the trolley damage and affect the trolley's life. So the cast iron materials require the characters of the high-temperature microstructure stability,oxidation resistance and wear-resistant property.

Cast iron materials with different microstructures have different performances. It is necessary to observe the microstructure of materials. As the best anti-abrasive wear materials, the high chromium cast iron materials have been widely applied [1]. The high chromium cast iron materials have been studied widely by more people, but the materials which are used in sintering machine trolley are rarely studied. Based on the high chromium cast iron materials for sintering machine trolley, the phase constitute and chemical composition of phases in materials were studied by means of the instruments (OM, SEM, XRD, EDS) in the paper.

\section{Experimental Materials and Methods}

The experimental materials are taken from the grate bar of sintering machine trolley. The experimental materials were cut to be small wafers of $\Phi 10 \mathrm{~mm} \times 3 \mathrm{~mm}$ by the wire cutting machine. Firstly, the sample was grinded by sandpaper, polished, and then eroded with 3\% nitric acid alcohol for 30-60s. After that, the sample was cleaned by the anhydrous alcohol. And finally, the sample was dried by a dryer. The microstructure of high chromium cast iron materials was observed with the help of the Axiovert 200 MAT optical microscope. The microstructure at high magnification was observed under the S-4800 field emission scanning electron microscope. With the help of the D/MAX2500PC X-ray diffraction, the chemical composition of every phase in the materials can be determined. And combined with the results of the energy spectrum analysis (EDS), the microstructure of the high chromium cast iron materials was determined.

\section{Experimental Results and Analysis}

Fig. 1 shows that the microstructure of the high chromium cast iron materials for sintering machine trolley is austenite,martensite, $\mathrm{Cr}_{7} \mathrm{C}_{3}, \mathrm{Fe}_{3} \mathrm{C},(\mathrm{Cr}, \mathrm{Fe})_{7} \mathrm{C}_{3}$. It can be seen from Fig.2 that the microstructure is composed by primary dendrites and the eutectic structures what grow in the 
interdendritic. Combined the energy spectroscopy analysis (EDS), as shown in Table 1, it can be determined that the primary dendrites are the primary austenite, the eutectic structures are the eutectic carbides and the martensite which austenite transform. The eutectic carbides are the cementite and $\mathrm{M}_{7} \mathrm{C}_{3}$-type carbides. The results show that the $\mathrm{M}_{7} \mathrm{C}_{3}$-type carbides are the $\mathrm{Cr}_{7} \mathrm{C}_{3},(\mathrm{Cr}, \mathrm{Fe})_{7} \mathrm{C}_{3}$, as shown in Fig. 1

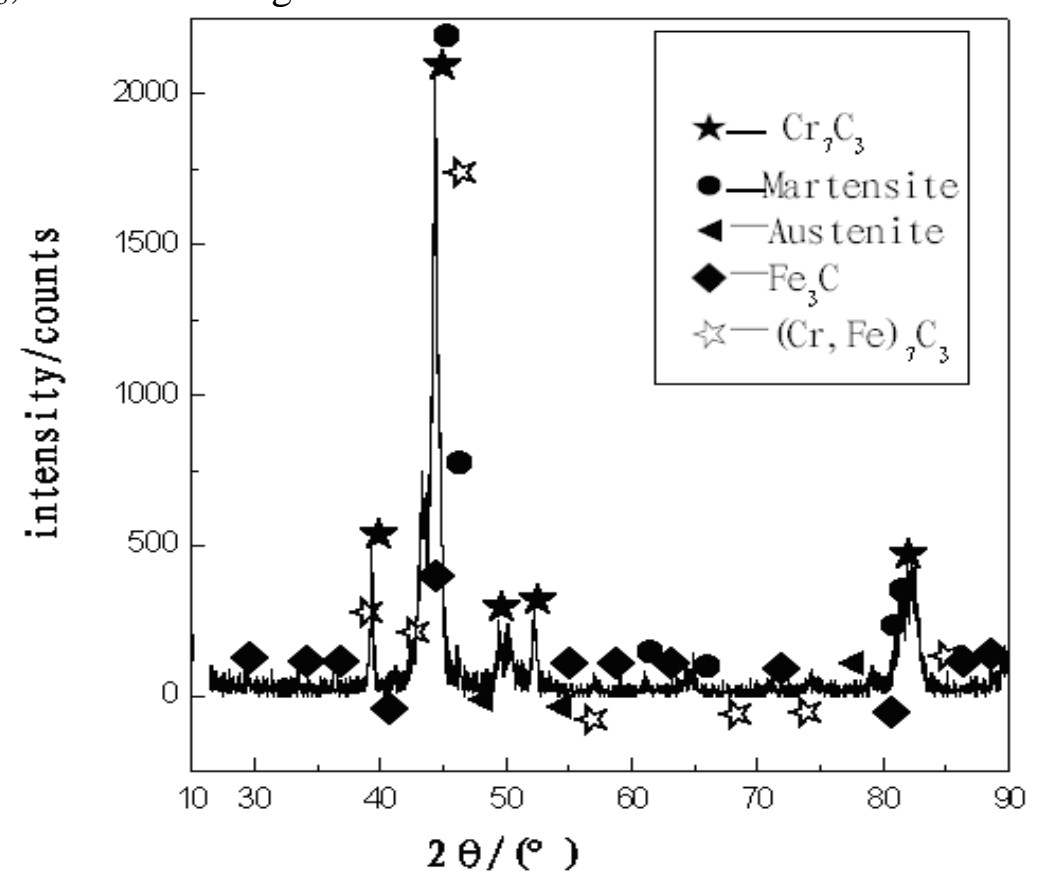

Fig.1 XRD diffraction pattern of the high chromium cast iron materials

Table 1 The chemical composition of each phase

\begin{tabular}{ccccc}
\hline Phase & $\mathrm{C}$ & $\mathrm{Si}$ & $\mathrm{Cr}$ & $\mathrm{Fe}$ \\
\hline $\mathrm{M}_{7} \mathrm{C}_{3}$ & 22.53 & & 51.65 & 25.82 \\
$\mathrm{Fe}_{3} \mathrm{C}$ & 22.25 & & 13.53 & 64.22 \\
Austenite & 2.55 & 0.68 & 12.23 & 84.54 \\
\hline
\end{tabular}

Fig. 1 shows that the martensite has been precipitated from the high chromium cast iron materials for sintering machine trolley. As a result of the formation of carbide in the microstructure, it is poor carbon and poor chromium around the carbide. In the eutectic reaction, due to the formation of cementite, the carbon and chromium which is on the edge of primary austenite and eutectic austenite diffuse to the carbide. With the temperature decreasing in the process of solidification, the diffused driving force is small and the atoms are not enough to migrate. The austenite contained saturated carbon and chromium, but the low carbon zones would be formed on the edge of the austenite. The martensite transformational temperature is increased due to the formation of low carbon zones. Therefore, a little martensite is formed in the process of solidification.
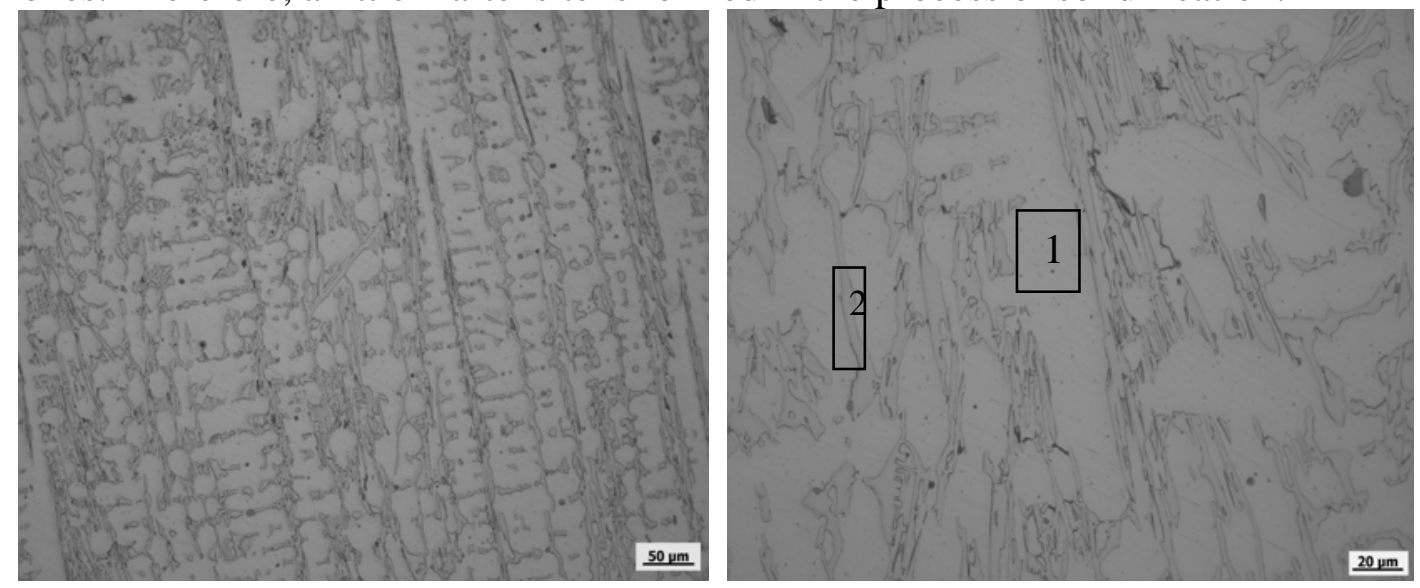

Fig.2 OM micrographs showing microstructure of the high chromium cast iron materials 
The microstructure was observed with the help of the Axiovert 200 MAT optical microscope, as shown in Fig.2. The chemical composition of primary dendrite is analyzed by the energy dispersive spectroscopy, as shown in Table 1. Combined the chemical composite shown in Table 1 and the microstructure shown in Fig.1, it can be determined that the primary dendrites are the primary austenite.

In the casting process, the primary austenite grows by the dendrite. The size,the number and the distribution of dendrites are decided by the solidification rate. A lot of chromium is contained in the high chromium cast iron materials. The constitutional supercooling is caused by the enrich chromium in the front of solidification. The growth of primary austenite and dendrite are decided by the constitutional supercooling [2]. As indicated in Fig.2 and Fig.3, there is a lot of dendritic primary austenite which is visible in matrix. That is because the matrix of high chromium cast iron is the austenite at room temperature. It is also to say that the austenite can be retained from high temperature to room temperature. Whether the primary austenite can be retained at room temperature or not, depending on the amount of carbon and chromium what are contained in the austenite. The microstructure of high chromium cast iron materials is from the non-equilibrium solidification process. In this process, austenite is precipitated firstly [3]. With the increasing of cooling rate and supercooling, the nucleation of primary austenite is more and more, and the austenite dendrite is refined. And with the melt being solidified in a short time, the solutes in the solid and liquid phases are not diffuse. In addition, the solutes which are in the solidification interface deviate from the equilibrium position. So the segregations of carbon and chromium are less during solidification process. Chromium is a stronger carbide forming element than iron, and it has a strong attraction to carbon [4]. For this reason, chromium can inhibit the carbon atom to diffuse from austenite to the liquid phase in the solidification process. Because the diffusion of atoms is difficult at low temperature, the enrich carbon and chromium are contained in the primary austenite. It also can be seen from Table 1 that the saturated carbon is contained in the austenite. Because the chromium is a strong carbide forming element, the austenite is too late to form ferrite [5]. The more carbon and chromium are contained in the austenite, the more austenite is stable.

The strips of eutectic structures which grow by the dendritic morphology are the cementite in the second zone, as shown in the Fig.2. The composition of the phase was in the Table 1.That will reach to the eutectic transformational temperature until the melt's temperature decrease to $1148^{\circ} \mathrm{C}$. And the eutectic transformation is occurred at the temperature. In the process, the liquid will be converted to a mixture of eutectic austenite and cementite. The eutectic cementite is directly crystallized from the liquid iron-carbon alloy. Eutectic cementite often grows strongly by dendritic morphology, because of the active liquid atoms. In the process of the forming cementite, the amount of carbon is too high (4.3\%) in the liquid alloy. Therefore there is a large number of eutectic cementite in the alloy.
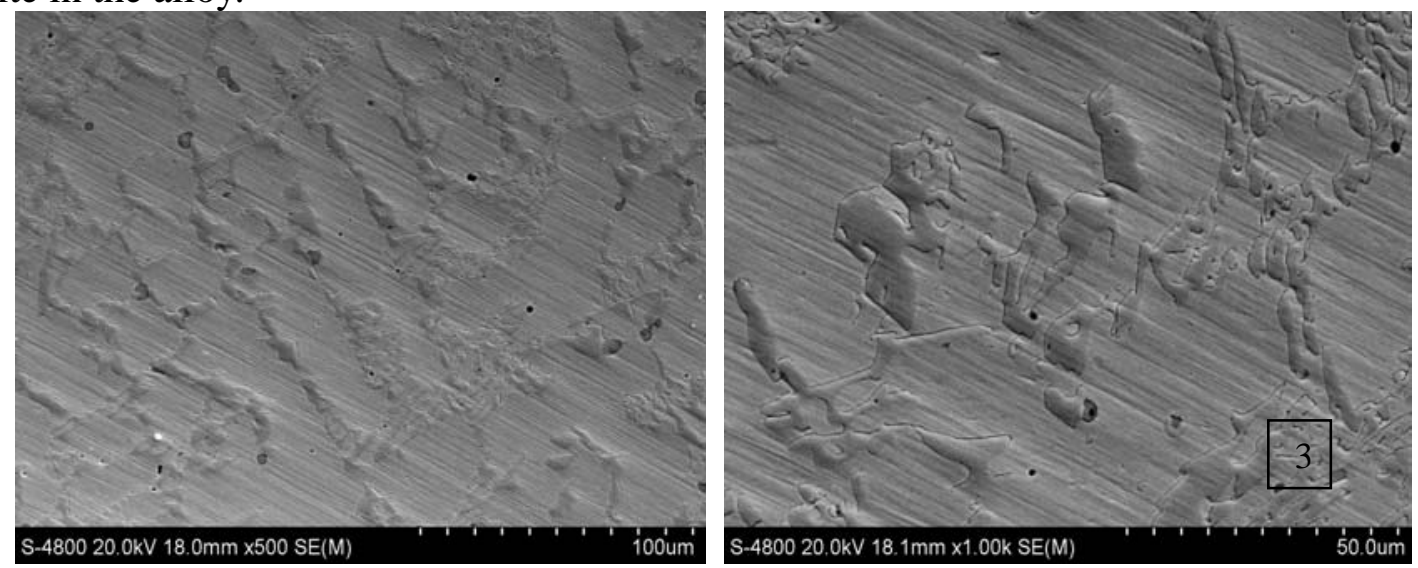

Fig.3 SEM micrographs showing microstructure of the high chromium cast iron materials

The microstructure was observed by means of the S-4800 field emission scanning electron microscope, as shown in Fig.3. The eutectic structure is the chrysanthemum shaped carbide at zone 3 in the Fig.3. According to the document and the result in the Table 1, the eutectic structure is the carbide of the $\mathrm{M}_{7} \mathrm{C}_{3}$ type. As shown in Fig.1, the eutectic carbides of high chromium cast iron 
materials are the type of $\mathrm{Cr}_{7} \mathrm{C}_{3},(\mathrm{Cr}, \mathrm{Fe})_{7} \mathrm{C}_{3}$. In the matrix, due to a lot of chromium which is the strong carbide forming element, it is easy to form the orthorhombic eutectic carbide of the $\mathrm{Cr}_{7} \mathrm{C}_{3}$ type. Combined with the carbon atoms, iron atoms are easy to form the unstable compounds of $\mathrm{Fe}_{7} \mathrm{C}_{3}$. Compared iron atoms and chromium atoms, their sizes are very close. So the chromium atoms can replace the iron atoms and form the carbides of $(\mathrm{Cr}, \mathrm{Fe})_{7} \mathrm{C}_{3}$ type [6]. The chromium can reduce the chemical potential about the carbon in iron, and therefore the $(\mathrm{Cr}, \mathrm{Fe}){ }_{7} \mathrm{C}_{3}$ can be existed in the microstructure. The hardness of carbide is (HV1500-HV1800) [7], so that the high chromium cast iron material has good abrasive wear performance, and improves the life of the sintering machine trolley.

\section{Conclusion}

(1) The microstructure of high chromium cast iron materials for sintering machine trolley is composite by primary austenite and eutectic structure.

(2) The martensite was precipitated on the edge of austenite in high chromium cast iron.

(3) The carbides which precipitated from high chromium cast iron, increase the hardness of the matrix, so the trolley has more abrasive performance.

\section{Acknowledgement}

This work was financially supported by Natural Science Foundation-Steel and Iron Foundation of Hebei Province (E2010000948).

\section{References}

[1] Zhang Yongsheng, Fu Hanguang. The research and application of resistant wear and heat of the high-chromium alloy grate [J], Studies on Foundry Equipment, 1998(2): 37-39.

[2] Chen Jingju, Xu Guangkui. Alloys of high chromium cast iron and application [M], Beijing: Metallurgical Industry Press, 1999,11-12.

[3] Ma Youping, Li Jun. Effects of carbon content variation on primary austenite stability of high chromium cast iron [J], Foundry, 2006,10(55):1080-1081.

[4] Ma Youping, Dang Xiaoming. Effects of cooling rate on stability of primary austenite of high chromium cast iron [J], ordnance material science and engineering, 2011,4(34):18-19.

[5] Zhang Zhaoyun, Xu Qingjie. Cognition about type D graphite gray cast iron [J], Foundry Technology, 2003(4):283-284.

[6] Zhao Feng. Study on forming mechanism and morphological characteristics of carbides during the solidification of high chromium cast irons [D].Xi An: Xi'an University of Architecture and Technology. 2007,8-9.

[7] Hao Shijian. Wear resistant High-chromium cast iron [M]. Beijing: Coal Industry Press, 1998, 87. 